\title{
Socioeconomic Status and Subclinical Atherosclerosis in Older
}

\section{Adults}

\author{
Scott D. Nash, MS ${ }^{1}$, Karen J. Cruickshanks, PhD ${ }^{1,2}$, Ronald Klein, MD, MPH ${ }^{2}$, Barbara E. \\ K. Klein, MD, MPH ${ }^{2}$, F. Javier Nieto, MD, PhD ${ }^{1}$, Carol D. Ryff, PhD ${ }^{3}$, Elizabeth M. Krantz, \\ MS $^{2}$, Carla R. Shubert, MS ${ }^{2}$, David M. Nondahl, $\mathbf{M S}^{2}$, and Charles W. Acher, MD ${ }^{4}$ \\ ${ }^{1}$ Department of Population Health Sciences, University of Wisconsin, Madison, WI \\ ${ }^{2}$ Department of Ophthalmology and Visual Sciences, University of Wisconsin, Madison, WI \\ ${ }^{3}$ Institute of Aging, University of Wisconsin, Madison, WI \\ ${ }^{4}$ Department of Surgery, University of Wisconsin, Madison, WI
}

\begin{abstract}
Objective-This study investigated the long-term effects of socioeconomic status (SES) on atherosclerosis.
\end{abstract}

Methods-Data from the Epidemiology of Hearing Loss Study and the Beaver Dam Eye Study (Beaver Dam, WI, 1998-2000), were used to examine adult SES (education, household income, longest-held job) and childhood SES (household density and parental home ownership at age 13) associations with carotid intima-media thickness (IMT) and carotid plaque in a cohort of 2,042 men and women aged 53 to 94 years.

Results-For education, income, and occupation (women), those in the lowest SES group had statistically larger age-sex-adjusted IMT than those in the highest SES group $(<12$ vs. $>12$ years education: 0.92 vs. $0.86 \mathrm{~mm}$ respectively, $P<0.0001),(<\$ 10,000$ vs. $>\$ 45,000: 0.97$ vs. $0.87 \mathrm{~mm}$, $P<0.0001$ ), (operator/fabricator/labor vs. manager/professional: 0.89 vs. $0.82 \mathrm{~mm}, P<0.001$ ). Associations were similar using carotid plaque as the outcome. Participants with low levels of both adult and childhood SES measures had age-sex-adjusted IMT greater than those with persistently high levels of SES (0.93 vs. $0.84 \mathrm{~mm}, P<0.0001)$.

Conclusions-Measures of SES at two points in the life-span were associated with subclinical atherosclerosis.

\section{Keywords}

Socioeconomic Status; Intima-media Thickness; Atherosclerosis; Carotid Artery plaque; Cardiovascular disease; Life-course epidemiology

Corresponding Author: Scott D. Nash MS, Population Health Sciences, University of Wisconsin-Madison, 610 Walnut St, 1036 WARF, Madison, WI 53726-2336, Tel: 608.262.6106, Fax: 608.265.2148, snash@wisc.edu.

Disclosure: None of the authors disclose any conflicts of interest.

Publisher's Disclaimer: This is a PDF file of an unedited manuscript that has been accepted for publication. As a service to our customers we are providing this early version of the manuscript. The manuscript will undergo copyediting, typesetting, and review of the resulting proof before it is published in its final citable form. Please note that during the production process errors may be discovered which could affect the content, and all legal disclaimers that apply to the journal pertain. 


\section{Introduction}

The association between socioeconomic status (SES) and cardiovascular disease (CVD) has been well documented (Kaplan and Kiel,1993) but more recent studies have focused on associations between SES and subclinical atherosclerosis measured by carotid artery intimamedia thickness (IMT) and plaque measurements (Carson et al., 2007; Diez-Roux et al., 1995; Kivimaki et al., 2006; Lamont et al., 2000; Lemelin et al., 2008; Lutsey et al., 2008; Lynch et al., 1995; Nordstrom et al., 2004; Rosvall et al., 2000; Rosvall et al., 2002). Although there appears to be an inverse relationship between SES and measures of subclinical atherosclerosis, inconsistencies exist based on gender (Lamont et al., 2000, Rosvall et al., 2000, Rosvall et al., 2002), race and ethnicity (Diez-Roux et al., 1995, Lemelin et al., 2008, Lutsey et al., 2008), and SES indicator (Diez-Roux et al., 1995, Kivimaki et al., 2006, Lemelin et al., 2008, Lamont et al., 2000, Rosvall et al., 2000).

Atherosclerosis has been detected in the young (Strong, 1992), so it may be warranted to study the impact of SES throughout the life-course. Because of the limited number of published life-course studies (Carson et al., 2007; Lemelin et al., 2008; Rosvall et al., 2002), especially in older adults, the purpose of this study was to determine the associations between markers of adult, childhood (at age 13 years), and cumulative life-course SES and carotid IMT and plaque in a population-based cohort of older adults in Beaver Dam, Wisconsin.

\section{Methods}

The Epidemiology of Hearing Loss Study (EHLS) began in 1993 in a population-based cohort developed for the Beaver Dam Eye Study (BDES). A private census conducted in 1987-88 identified residents of the city or township of Beaver Dam 43 to 84 years of age $(n=5,924)$ who were then invited to participate in the BDES $(n=4,926)($ Klein, 1994). Participants alive as of March 1, 1993 were eligible for the EHLS. Of these, 3,753 people (82.6\%) participated in the baseline examination (1993-1995), 2,800 people participated in the 5-year follow-up (EHLS2 1998-2000), and 2,395 people participated in the 10-year follow-up examination (EHLS3 2003-2005). Data from the EHLS and concurrent BDES examinations were included in these analyses of the 2,042 EHLS2 participants with IMT measurements. These studies were approved by the University of Wisconsin-Madison Internal Review Board.

Educational status obtained at the baseline BDES was categorized as $<12$ years, 12 years, and $>12$ years of school completed. At the baseline EHLS, the type of work done the longest was coded by 1980 census classifications; homemakers were coded with service occupations. Household annual incomes from 1998-2000 (EHLS2), were used. At EHLS3, participants were asked: "When you were age 13, how many people lived in your home?" and "When you were age 13, how many bedrooms were in your home?" Childhood household density was defined as the number of people living in the home divided by the number of bedrooms in the home, then split at the median. Participants were also asked if at age 13, their parents rented or owned their home.

High resolution B-mode carotid artery ultrasound images (Biosound AU4, Biosound Esaote, Indianapolis, IN USA) were obtained at EHLS2 by a certified sonographer using a modification of the Atherosclerosis Risk In Communities (ARIC) study protocol (Bond, 1991). The areas of focus were the $1 \mathrm{~cm}$ of the distal common carotid artery (CCA) closest to the bifurcation, the bifurcation, and $1 \mathrm{~cm}$ of the proximal internal carotid artery (ICA) closest to the flow divider. IMT and plaque measurements were made by certified graders using a custom program interfaced with ImagePro software (Image Pro Plus version 4.1. 
Media Cybernetics, Silver Spring, MD USA), and a modified ARIC protocol (Riley, 1991). Mean IMT was defined as the mean of the near and far walls of the CCA, the bifurcation and the ICA on both the left and right sides. Mean inter-grader difference in IMT was 0.03 $\mathrm{mm}$. Plaque was determined by evaluating change in wall shape, change in wall texture, and wall thickness (greater than or equal to $1.5 \mathrm{~mm}$ ). Plaque was considered present if one of these was present with acoustic shadowing, or two were observed in an area without acoustic shadowing. The number of sites (left and right CCA, ICA, and bifurcation) with plaque was categorized: 0, 1-3 and 4-6 sites. Inter-grader reliability for plaque was excellent; kappas averaged 0.76 and percent agreement averaged 90\%. IMT measures were available for 2,042 (73\%) participants. Ultrasounds were not obtained for participants unable to come to the central site, unable to lay flat, or when the sonographer was unavailable.

Cardiovascular risk factors were measured at the same study phase as IMT measurements. History of CVD was a self-reported physician-diagnosed stroke, myocardial infarction (MI), or angina. Family history of CVD was positive if either parent had had a stroke or MI. Blood pressure was measured using the Hypertension Detection and Follow-up Protocol (HDFP, 1976). Hypertension was defined as systolic blood pressure $\geq 140 \mathrm{mmHg}$, diastolic blood pressure $\geq 90 \mathrm{mmHg}$, or physician-diagnosed hypertension and current use of hypertension medication. Diabetes status was defined as self-report of physician-diagnosed and treated diabetes or elevated glycated hemoglobin levels using age- and sex- adjusted norms (Klein, 1992). Body mass index (BMI) was calculated as weight in kilograms divided by height in meters squared, with obesity defined as BMI $\geq 30 \mathrm{~kg} / \mathrm{m}^{2}$. Total and HDL cholesterol were measured using reflectance spectrophotometry. Pack-years were calculated for smokers. History of heavy drinking meant having consumed four or more alcoholic beverages daily at any point in life.

All analyses were performed with SAS version 9.1 (SAS Institute, Cary NC). Participants with and without IMT measurements were compared using chi-square, Cochran-MantelHaenszel, t-test and linear regression procedures. Multivariable least squares regression was used to test for associations between SES indicators and IMT. Ordinal logistic regression (the cumulative odds model) was used to estimate odds ratios and examine the associations between SES indicators and plaque score. Model 1 adjusted for age and sex, and model 2 adjusted for age, sex and traditional CVD risk factors (family history of CVD, prevalent CVD, diabetes status, hypertension, HDL and non-HDL cholesterol, pack-years of smoking (non-smokers coded as 0), and history of heavy drinking) in order to determine if SES associations were independent of these known risk factors. Analyses were repeated in a subgroup of participants without CVD, to examine associations in the healthiest participants. Based on the results of the separate childhood and adult SES analysis, an accumulation of risk model (Ben-Schlomo, 2002; Roswall, 2002) was built using the combined "exposures" of childhood household density and education as they were the most consistent childhood and adult SES indicators respectively in their associations with carotid IMT and plaque. An ordinal variable with six categories was created according to the possible groupings of 2 levels of density split at the median value $(\leq 1.5$ people/bedroom, $>1.5$ people/bedroom), and 3 levels of education ( $<12$ years, 12 years, $>12$ years) with the group having low density and $>12$ years of education as the referent group.

\section{Results}

Comparisons between EHLS2 and previous phases have been published (Cruickshanks et al., 1998; Cruickshanks et al., 2003). Retention rates among survivors remained high throughout the study (82-83\%) and participants tended to be younger, more often female, have higher SES, and less likely to smoke than non-participants (Cruickshanks et al., 1998; Cruickshanks et al., 2003). Adjusting for age and sex, EHLS2 participants with IMT 
measurements were more educated $(P<0.001)$, had higher HDL-cholesterol levels $(P<$ $0.05)$ and were less likely to have had a history of CVD $(P<0.01)$ than EHLS2 participants without an IMT measurement (Table 1). Amongst participants with IMT measurements, those who provided childhood SES information five years later were younger, more educated, less likely to have diabetes, and had lower IMT at EHLS2 (data not shown) than nonparticipants at EHLS3.

Participants in the lowest education group had larger age-sex-adjusted IMT $(0.918 \mathrm{~mm}$ vs. $0.858 \mathrm{~mm} ; P<0.001$ ) (Table 2), and were more likely to have higher plaque scores $(\mathrm{OR}=1.9,95 \% \mathrm{CI}: 1.5,2.5)$ than those in the highest education group. In stratified analyses based on the number of sites with plaque $(\leq 1$ and $>1)$, lower education remained significantly associated with the larger IMT (data not shown). IMT ranged from $0.969 \mathrm{~mm}$ in the lowest income category $(<\$ 10,000)$ to $0.866 \mathrm{~mm}$ in the highest category $(>\$ 45,000)$ $(P$ for trend $<0.001)$ in age- and sex-adjusted analyses. Results were similar when excluding retired participants (data not shown). A significant interaction was found between sex and occupation $(P<0.05)$. In stratified analyses, associations with IMT were significant in women only ( $P$ for trend $<0.0001$ ). Because homemakers may be different than service employees, occupation models were rerun excluding homemakers and results were similar (data not shown). In analyses excluding participants with prevalent CVD, effect sizes were somewhat attenuated, but remained statistically significant (data not shown).

Those above the median household density had larger IMT than those below after adjusting for age and sex $(P<0.05)$ and CVD risk factors $(P<0.05)$, but only a borderline association with plaque (Table 3 ). There were no statistically significant associations between parental home ownership and IMT or plaque.

Those with higher household density during childhood, and $<12$ years of education (low SES at each time) had statistically significant larger IMT than those with low childhood and high adult SES $(0.926 \mathrm{~mm}$ vs. $0.844 \mathrm{~mm} ; P=0.0001)$ and those with high SES at each time $(0.926 \mathrm{~mm}$ vs. $0.840 \mathrm{~mm} ; P<0.0001)$ (Table 4$)$. The odds of higher plaque score were 2.1 times higher $(95 \%$ CI 1.3,3.1) for those with low childhood and high adult SES, and 2.6 times (95\%CI: $1.7,3.9)$ higher than those with the highest SES at both times. Estimates were similar when CVD risk factors were included in the model.

\section{Discussion}

Higher SES as measured by education, income, and longest held job (in women) was significantly associated with larger IMT and higher plaque score. Associations between childhood SES and atherosclerosis were less consistent. However, IMT was $0.09 \mathrm{~mm}$ greater in participants with low SES at each time point compared to those with high SES at each time point. This difference in IMT is likely to be clinically meaningful since a $0.1 \mathrm{~mm}$ increase in IMT may increase the risk of MI by $15 \%$ and of stroke by $18 \%$ (Lorenz et al., 2007). These population-based findings are consistent with other studies showing increased subclinical atherosclerosis in those with persistently low life-course SES (Carson et al., 2007; Lemelin et al., 2008; Rosvall et al., 2002).

Education showed a graded statistically significant inverse association that remained after adjustment for age and sex, and CVD risk factors similar to previous reports (Diez-Roux et al., 1995; Nordstrom et al., 2004; Lutsey et al., 2008; Lynch et al., 1995). For income and occupation in women, the lowest SES group had larger IMT than the highest group but relationships were inconsistent across SES categories. Income may not be a good measure of SES among older, retired persons as atherosclerosis could force people into a "downward drift" in income. Results of analyses in the subgroup of people without prevalent CVD were 
similar, suggesting this was unlikely. Sex differences for occupation may be due to sex differences in psychosocial working conditions, and occupational stress interactions with other gender-specific factors (Diez-Roux et al., 1995).

Household density, a marker of childhood SES (higher density, lower SES) was inversely associated with IMT and plaque score. Household density has been used as a proxy for childhood SES in previous epidemiological studies (Dedman et al., 2001; Frenkel et al., 1999; Galobardes et al., 2004; Galobardes et al., 2006). It is also a measure of childhood conditions (crowding), and has been linked to an increase in infections, and adult height; a predictor of future chronic illnesses (Dedman et al., 2001). Parental home ownership was not associated with atherosclerosis. Home ownership may not be a strong indicator of SES as neither housing value nor neighborhood factors are considered in this measure. Parental education and occupation were unavailable.

Participants with low SES in childhood and as an adult had the largest IMT measurements and highest plaque scores, suggesting that SES factors in childhood may be associated with atherosclerosis. Participants with low childhood SES who attained high educational levels had statistically lower IMT measurements and plaque scores than those who did not complete high school. These results are consistent with the hypothesis that education may facilitate positive social, psychological and economic skills (Krieger, 1997), which in turn may help compensate for lower SES levels in childhood.

Childhood SES measures may be useful in studies of the etiology of atherosclerosis which develops slowly over the life-time. SES probably operates through traditional CVD risk factors (smoking, cholesterol, etc.) (Diez-Roux et al., 1995). However, in EHLS participants, significant associations remained after adjusting for these factors. These may be due to imprecise measurement or the cross-sectional nature of the risk factor measurements which miss the accumulation of such factors over the lifetime (Lynch et al., 1996) but differences in medical care, genetic, environmental, and psychosocial factors including social support, depression, job strain, and chronic stress (Kaplan and Kiel, 1993) may also contribute. These factors may help explain how low SES has negative biological consequences such as elevated levels of inflammatory markers (Taylor et al., 2006), increased oxidative stress and decreased levels of anti-oxidants (Janicki-Deverts et al., 2009) that may lead to increased CVD risk.

\section{Strengths and Limitations}

This population-based cohort study had high participation and retention rates, used standardized measures of carotid artery atherosclerosis and had multiple measures of SES about two separate points in life. Our results may have been affected by survivor bias. Participants without IMT measures were less educated, older, and had a higher prevalence of CVD which may have led to underestimation of associations. IMT and plaque were not independent measures so results may be reflecting the effects of plaque rather than generalized low levels of thickening but models stratified by amount of plaque $(\leq 1$ site and $>1$ site) demonstrated similar IMT trends across SES levels. Other limitations include the possibility of recall bias for childhood SES, the inability to characterize neighborhood SES due to the size of the community, and the fact that this study was limited to one IMT measurement. Despite these limitations this study adds to the evidence that childhood SES coupled with adult SES may have long-term implications for adult health.

\section{Conclusion}

Both childhood and adult SES were associated with subclinical atherosclerosis and the effect was greatest among those with consistently low SES. Further research is needed to 
determine the mediating factors that link life-long low levels of SES and poorer cardiovascular health.

\section{Acknowledgments}

Sources of Funding: The project described was supported by Award Number R37AG011099 (K.J.C.) and EY06594 (R.K. B.E.K.K.) from the National Institute On Aging and the National Eye Institute. The content is solely the responsibility of the authors and does not necessarily represent the official views of the National Institute On Aging, the National Eye Institute, or the National Institutes of Health.

\section{References}

Ben-Schlomo Y, Kuh D. A life course approach to chronic disease epidemiology: conceptual models, empirical challenges and interdisciplinary perspectives. International Journal of Epidemiology. 2002; 31:285-293. [PubMed: 11980781]

Bond MG, Barnes RW, Riley WA, Wilmoth SK, Chambless LE, Howard G, Owens B. High resolution b-mode ultrasound scanning procedure in atherosclerosis risk in communities (ARIC) study. J Neuroimag. 1991; 1:68-73.

Carson AP, Rose KM, Catellier DJ, Kaufman JS, Wyatt SB, Diez-Roux AV, Heiss G. Cumulative socioeconomic status across the life course and subclincal atherosclerosis. Ann Epidemiol. 2007; 17:296-303. [PubMed: 17027292]

Cruickshanks KJ, Wiley TL, Tweed TS, Klein BEK, Klein R, Mares-Perlman JA, Nondahl DM. Prevalence of hearing loss in older adults in Beaver Dam, WI. The Epidemiology of Hearing Loss Study. Am J Epidem. 1998; 148(9):879-885.

Cruickshanks KJ, Tweed TS, Wiley TL, Klein BE, Klein R, Chappell R, Nondahl DM, Dalton DS. The 5-year incidence and progression of hearing loss: the epidemiology of hearing loss study. Arch Otolaryngol Head Neck Surg. 2003; 129(10):1041-6. [PubMed: 14568784]

Dedman DJ, Gunnell D, Davey Smith G, Frenkel S. Childhood housing conditions and later mortality in the Boyd Orr cohort. J Epidemiol Community Health. 2001; 55:10-15. [PubMed: 11112945]

Diez-Roux AV, Nieto FJ, Tyroler HA, Crum LD, Szklo M. Social Inequalities and Atherosclerosis. The atherosclerosis risk in communities study. Am J Epidemiol. 1995; 141:960-972. [PubMed: 7741126]

Frenkel S, Davey Smith G, Gunnell D. Childhood socioeconomic position and adult cardiovascular mortality: The Boyd Orr cohort. Am J Epidemiol. 1999; 150:1081-1084. [PubMed: 10568623]

Galobardes B, Lynch JW, Davey Smith G. Childhood socioeconomic circumstances and cause-specific mortality in adulthood: systematic review and interpretation. Epidemiol Rev. 2004; 26:7-21. [PubMed: 15234944]

Galobardes B, Davey Smith G, Lynch JW. Systematic review of the influence of childhood socioeconomic circumstances on risk for cardiovascular disease in adulthood. Ann Epidemiol. 2006; 16(2):91-104. [PubMed: 16257232]

Hypertension Detection and Follow-Up Program Cooperative Group: The Hypertension Detection and Follow-Up Program. Prev Med. 1976; 5:207-215. [PubMed: 935073]

Janicki-Deverts D, Cohen S, Matthews KA, Gross MD, Jacobs DR Jr. Socioeconomic status, antioxidant micronutrients, and correlates of oxidative damage: the Coronary Artery Risk Development in Young Adults (CARDIA) study. Psychosom Med. 2009; 71(5):541-548. [PubMed: 19414620]

Kaplan GA, Keil JE. Socioeconomic factors and cardiovascular disease: a review of the literature. Circulation. 1993; 88:1973-1998. [PubMed: 8403348]

Kivimaki M, Davey Smith G, Juonala M, Ferrie JE, Keltikangas-Jarvinen, Elovainio M, PulkkiRaback L, Vahtera J, Leino M, Viikari JSS, Raitakari OT. Socioeconomic position in childhood and adult cardiovascular risk factors, vascular structure, and function: cardiovascular risk in young Finns study. Heart. 2006; 92:474-480. [PubMed: 16159979]

Klein R, Klein BEK, Moss SE, Linton KLP. The Beaver Dam Eye Study. Retinopathy in adults with newly discovered and previously diagnosed diabetes mellitus. Ophthalmology. 1992; 99:58-62. [PubMed: 1741141] 
Klein R, Klein BEK, Jensen SC, Moss SE, Cruickshanks KJ. The relation of socioeconomic factors to age-related cataract, maculopathy, and impaired vision. Ophthalmology. 1994; 101(12):19691979. [PubMed: 7997336]

Krieger N, Williams DR, Moss NE. Measuring social class in US public health research. Annu Rev Public Health. 1997; 18:341-378. [PubMed: 9143723]

Lamont D, Parker L, White M, Unwin N, Bennnett SMA, Cohen M, Richardson D, Dickinson HO, Adamson A, Alberti KGMM, Craft AW. Risk of cardiovascular disease measured by carotid intima-media thickness at age 49-51: lifecourse study. BMJ. 2000; 320:273-278. [PubMed: 10650022]

Lemelin ET, Diez-Roux AV, Franklin TG, Carnethon M, Lutsey PL, Ni H, O'Meara E, Shrager S. Life-course socioeconomic positions and subclinical atherosclerosis in the multi-ethnic study of atherosclerosis. Soc Sci Med. 2008; 68(3):444-451. [PubMed: 19081660]

Lorenz MW, Markus HS, Bots ML, Rosvall M, Sitzer M. Prediction of clinical cardiovascular events with carotid intima-media thickness: A systematic review and meta-analysis. Circulation. 2007; 115:459-467. [PubMed: 17242284]

Lutsey PL, Diex-Roux AV, Jacobs DR, Burke GL, Harman J, Shea S, Folsom AR. Associations of acculturation and socioeconomic status with subclinical cardiovascular disease in the multi-ethnic study of atherosclerosis. Am J Public Health. 2008; 98(11):1963-1970. [PubMed: 18511718]

Lynch J, Kaplan GA, Salonen R, Cohen RD, Salonen JT. Socioeconomic status and carotid atherosclerosis. Circulation. 1995; 92:1786-1792. [PubMed: 7671362]

Lynch JW, Kaplan GA, Cohen RD, Tuomileho J, Salonen JT. Do cardiovascular risk factors explain the relation between socioeconomic status, risk of all-cause mortality, cardiovascular mortality, and acute myocardial infarction? Am J Epidemiol. 1996; 144:943-942. [PubMed: 8916505]

Nordstrom CK, Diez Roux AV, Jackson SA, Gardin JM. The association of personal and neighborhood socioeconomic indicators with subclinical cardiovascular disease in an elderly cohort. The cardiovascular health study. Soc Sci Med. 2004; 59:2139-2147. [PubMed: 15351479]

Riley WA, Barnes RW, Bond MG, Evans G, Chambless LE, Heiss G. High resolution b-mode ultrasound reading methods in the atherosclerosis risk in communities (ARIC) cohort. J Neuroimag. 1991; 1:168-172.

Rosvall M, Ostergren PO, Hedblad B, Isacsson SO, Janzon L, Berglund G. Occupational status, education level, and the prevalence of carotid atherosclerosis in a general population sample of middle-aged Swedish men and women: Results from the Malmo diet and cancer study. Am J Epidemiol. 2000; 152:334-346. [PubMed: 10968378]

Rosvall M, Ostergren PO, Hedblad B, Isacsson SO, Janzon L, Berglund G. Life-course perspective on socioeconomic differences in carotid atherosclerosis. Arterioscler Throm Vasc Biol. 2002; 22:1704-1711.

Strong JP. Atherosclerotic lesions. Natural history, risk factors and topography. Arch Pathol Lab Med. 1992; 116:1268-1275. [PubMed: 1456871]

Taylor SE, Lehman BJ, Kiefe CI, Seeman TE. Relationship of early life stress and psychological functioning to adult c-reactive protein in the coronary artery risk development in young adults study. Biol Psychiatry. 2006; 60(8):819-824. [PubMed: 16712805]

\section{Abbreviations}

$\begin{array}{ll}\text { SES } & \text { Socioeconomic status } \\ \text { CVD } & \text { Cardiovascular Disease } \\ \text { IMT } & \text { intima media thickness } \\ \text { CCA } & \text { common carotid artery } \\ \text { ICA } & \text { internal carotid artery } \\ \text { MI } & \text { myocardial infarction } \\ \text { BMI } & \text { body mass index }\end{array}$




$\begin{array}{ll}\text { HDL } & \text { high density lipoprotein } \\ \text { OR } & \text { odds ratio } \\ \text { CI } & \text { confidence interval } \\ \text { SEM } & \text { standard error of the mean }\end{array}$


Table 1

Means and Prevalence of Select Characteristics between Participants with IMT Measurements and Participants without IMT Measurements in the Epidemiology of Hearing Loss Study, Beaver Dam, WI 1998-2000

\begin{tabular}{|c|c|c|c|c|}
\hline Characteristic & $\begin{array}{c}\text { IMT } \\
(\mathrm{n}=\mathbf{2 , 0 4 2})^{*}\end{array}$ & $\begin{array}{l}\text { No IMT } \\
(n=758) *\end{array}$ & $P$ Value ${ }^{a}$ & $P$ Value $^{b}$ \\
\hline Age, yr, mean & 68.1 & 72.6 & $<0.0001$ & \\
\hline $\operatorname{Sex} n(\%)$ & & & $<0.01$ & 0.074 \\
\hline Male & $879(43.1)$ & $279(36.8)$ & & \\
\hline Female & $1163(57.0)$ & $479(63.2)$ & & \\
\hline Education Years n $(\%)$ & & & $<0.0001$ & $<0.001$ \\
\hline$<12$ & $342(16.8)$ & $210(27.7)$ & & \\
\hline 12 & $996(48.8)$ & $333(44.0)$ & & \\
\hline$>12$ & $703(34.5)$ & $214(28.3)$ & & \\
\hline Longest Held Job n(\%) & & & 0.033 & 0.171 \\
\hline Operator/fabricator/labor & $362(18.5)$ & 155 (21.6) & & \\
\hline Production/Craft/Repair/Farming & $282(14.4)$ & $98(13.7)$ & & \\
\hline Service & $384(19.6)$ & $166(23.2)$ & & \\
\hline Technical/Sales/Administration & $500(25.6)$ & $172(24.0)$ & & \\
\hline Management/Professional & $427(21.8)$ & $126(17.6)$ & & \\
\hline Income $\mathrm{n}(\%)$ & & & $<0.0001$ & 0.003 \\
\hline$\$<10,000$ & $89(4.9)$ & $62(10.9)$ & & \\
\hline$\$ 10-19,000$ & $349(19.1)$ & $141(24.8)$ & & \\
\hline$\$ 20-29,000$ & $378(20.7)$ & $103(18.1)$ & & \\
\hline$\$ 30-44,000$ & $391(21.5)$ & $124(21.8)$ & & \\
\hline$\$>45,000$ & $616(33.8)$ & $139(24.4)$ & & \\
\hline Marital Status n(\%) & & & $<0.0001$ & 0.028 \\
\hline Never & $66(3.3)$ & $29(4.3)$ & & \\
\hline Married & $1383(69.1)$ & $365(54.6)$ & & \\
\hline Separated/Divorced & $146(7.3)$ & $62(9.3)$ & & \\
\hline Widowed & $406(20.3)$ & $213(31.8)$ & & \\
\hline Hypertension present $\mathrm{n}(\%)$ & $1201(58.8)$ & $409(64.3)$ & 0.014 & 0.505 \\
\hline Diabetes present $\mathrm{n}(\%)$ & $229(11.6)$ & $87(14.3)$ & 0.071 & 0.091 \\
\hline BMI kg/m², mean & 30.0 & 29.6 & 0.192 & 0.795 \\
\hline History of CVD n(\%) & $302(15.1)$ & $150(22.8)$ & $<0.0001$ & 0.008 \\
\hline Current or Past Smoker $\mathrm{n}(\%)$ & $1065(53.2)$ & $326(49.0)$ & 0.060 & 0.976 \\
\hline Non-HDL cholesterol mg/dl, mean & 163.00 & 160.60 & 0.223 & 0.286 \\
\hline HDL Cholesterol mg/dl, mean & 50.82 & 49.14 & 0.03 & 0.012 \\
\hline
\end{tabular}

Abbreviations: IMT, Intima-media thickness; BMI, Body Mass Index; CVD, cardiovascular disease; HDL, high density lipoprotein.

$a_{\text {Unadjusted }}$

${ }^{b}$ Age-adjusted for sex, and Age- and Sex-Adjusted for all others;

* sample size may differ for each participant characteristic due to missing data 


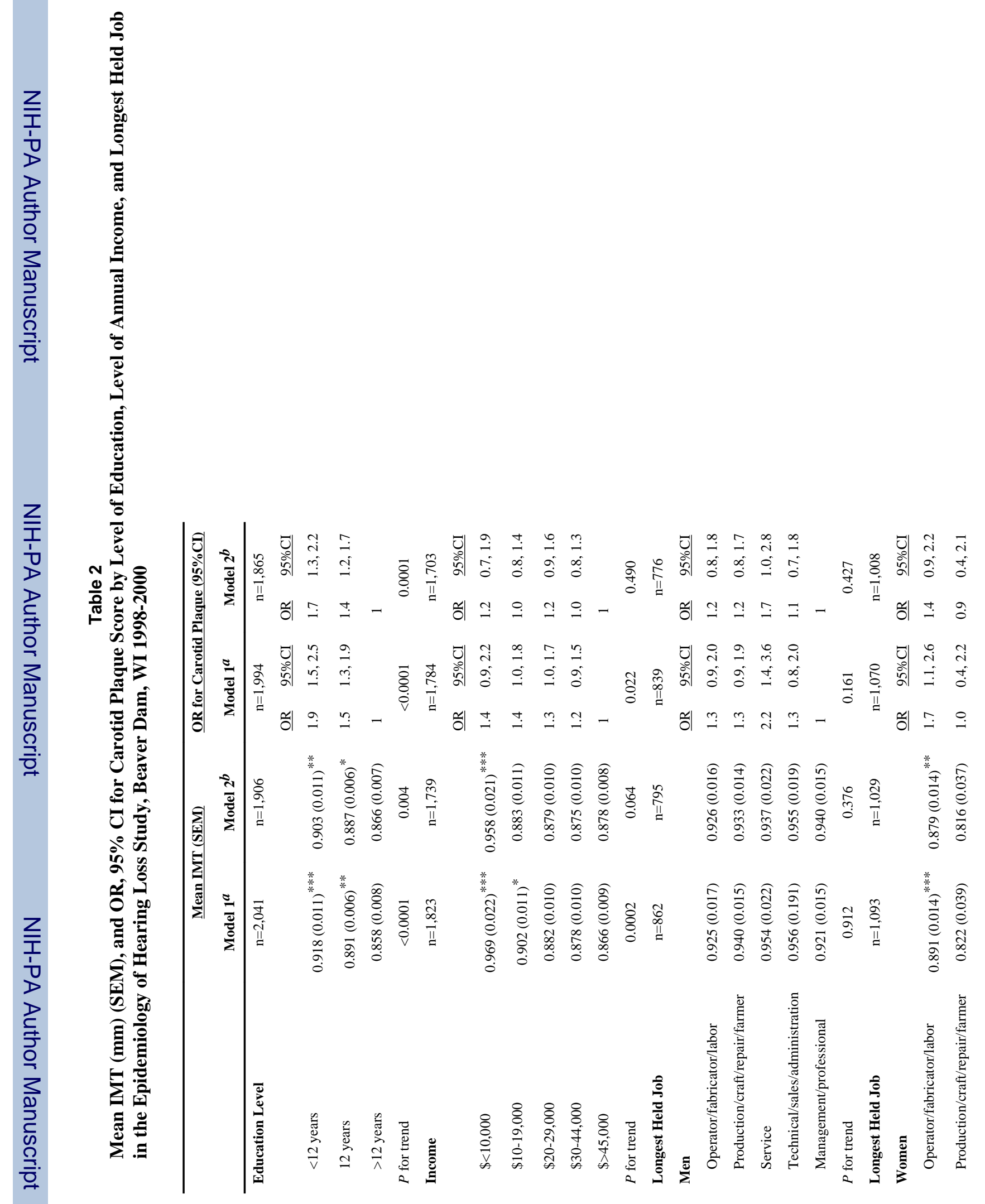




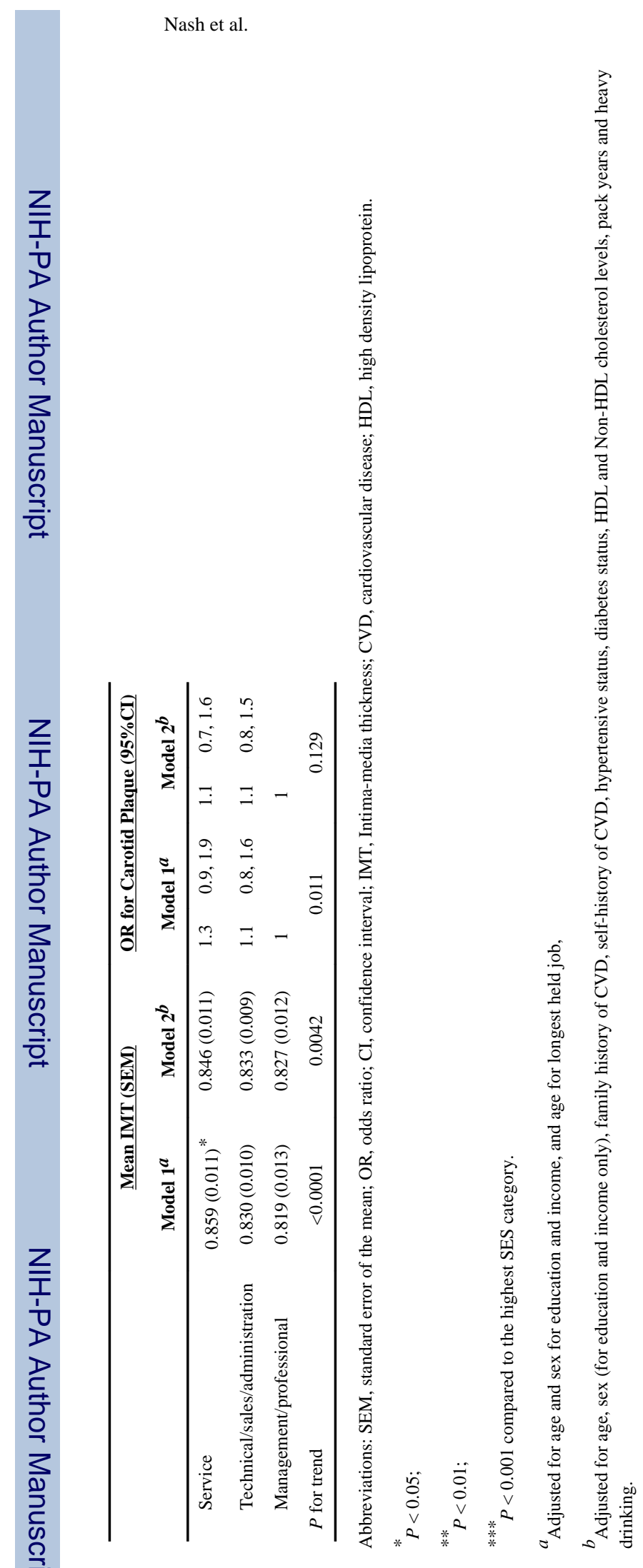

Prev Med. Author manuscript; available in PMC 2012 March 1. 


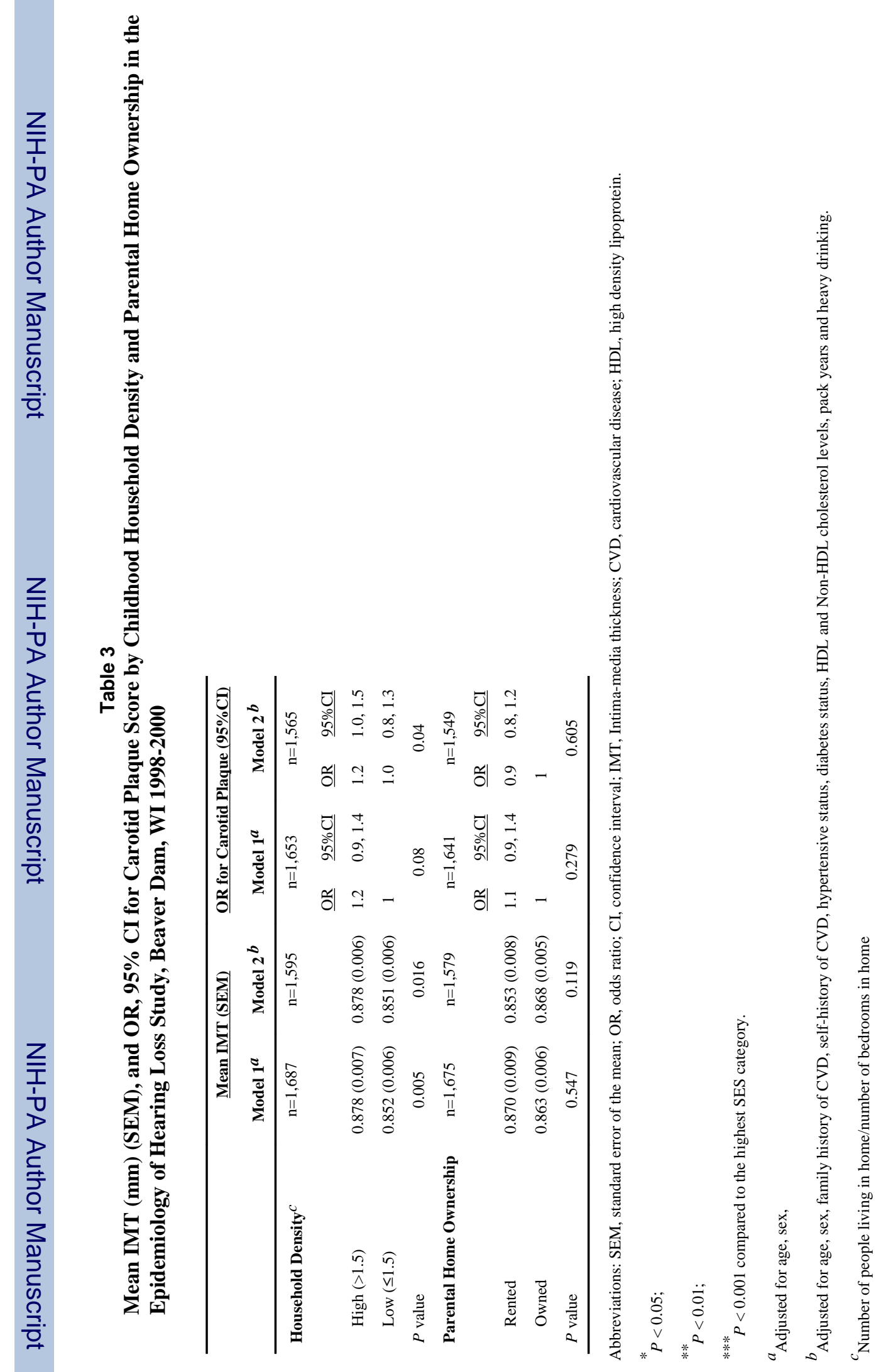

Prev Med. Author manuscript; available in PMC 2012 March 1. 


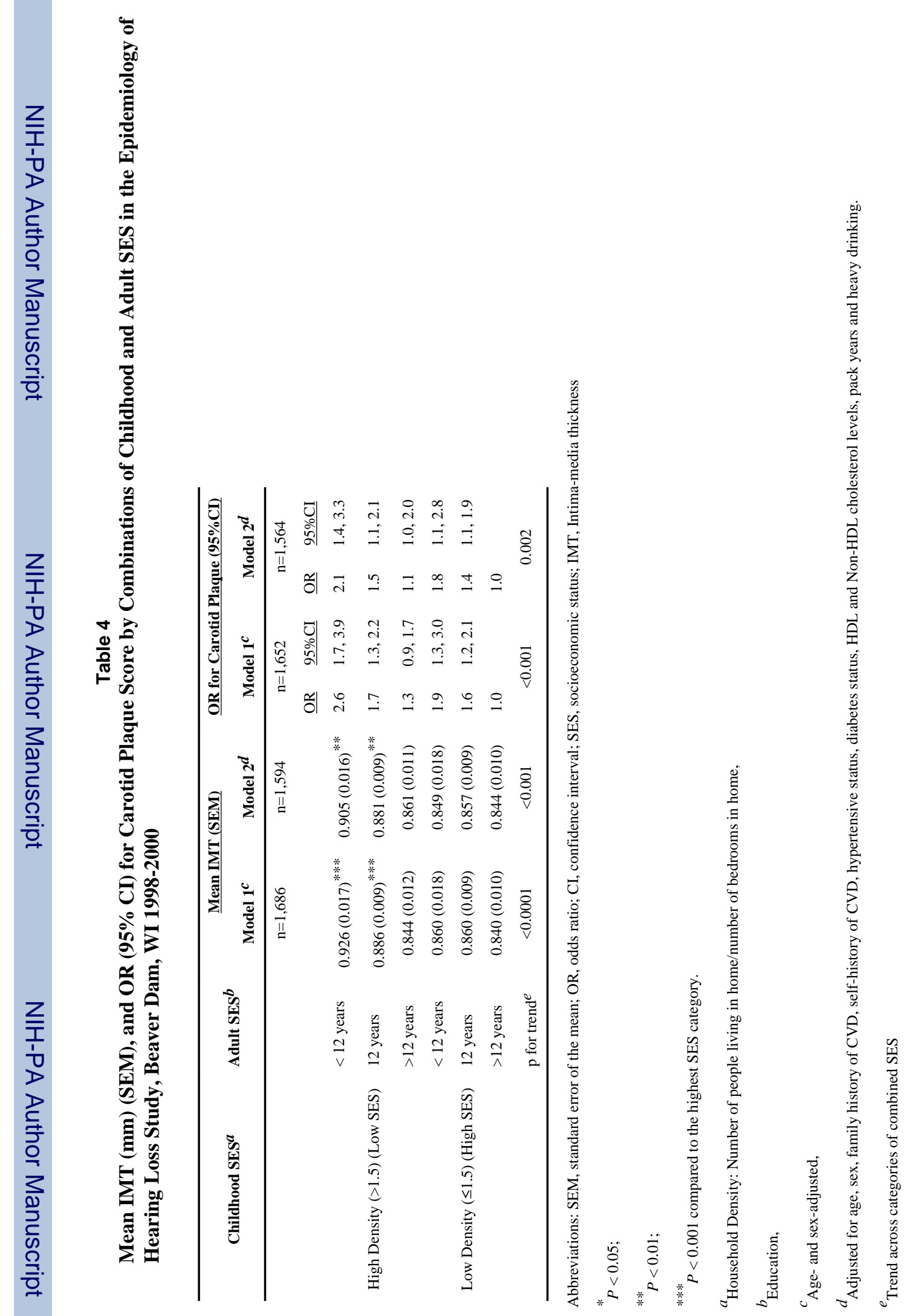

Prev Med. Author manuscript; available in PMC 2012 March 1. 